\title{
INFLUENCE OF DISPERSED HEAT-RESISTANT ADDITIVES ON IGNITION AND COMBUSTION OF HETEROGENEOUS SYSTEMS
}

\author{
V.A. Arkhipov, A.L. Astakhov, V.T. Kuznetsov \\ National Research Tomsk State University, Tomsk, Russia
}

\begin{abstract}
The results of experimental studies of the effect of dispersion of heat-resistant additives powders on ignition and combustion of heterogeneous condensed systems. The method of measuring the time delay ignition conductive and radiant heating, and combustion rate at atmospheric pressure. The effect of additives powders of boron, silicon and titanium dioxide on the ignition and combustion of heterogeneous condensed systems.
\end{abstract}

\section{Introduction}

To control the burning rate and improve the energy characteristics of heterogeneous condensed systems (HS) in their formulation is different supplements in the form of metal powders [Al, B, Si, etc.]. The degree of influence of these additives depends significantly on the dispersion of powders introduced [1-3]. The most extensively studied the effect of dispersion powder $\mathrm{Al}$ [3]. In this work the ignition and combustion of heterogeneous condensed systems with the introduction of heat-resistant additives - powder of boron, silicon, and titanium dioxide with high melting point.

In assessing the effective influence of the chemical nature of solid heat-resistant additive processes of ignition and combustion of mixed composition should be taken into account the degree of dispersion of the substance, as it is known [1] that the dispersion of solids can significantly affect the chemical activity. However, if the surface burning fine particles agglomerate into larger ones, the role of dispersion of the additive in the combustion process is negligible, since the activity of the additive determined by the size of the secondary particles (agglomerates) [2]. In the case where the agglomeration of fine particles is difficult, the developed surface of the introduced additives improves ignitability and burning velocity mix composition [3].

\section{HS samples}

In this paper, the effect of dispersion of heat-resistant additives on ignition and combustion of heterogeneous systems was investigated by the example of metallic blend compositions containing up to 15 wt $\%$ of aluminum, ammonium perchlorate, and butadiene rubber binder SKDM-80 (part M).

When manufacturing model compounds used ammonium perchlorate bidisperse particle size (160-315) microns and less than 50 microns in a ratio of 60/40 respectively. As the heat-resistant additives taken powders boron, silicon, and titanium dioxide. Additives in an amount of $5 \mathrm{wt} \%$ was introduced into the composition by reducing the content of aluminum. Characteristics of dispersion of additives are given in Table 1. The model compositions were prepared by mixing in a mixer of the "Beken" followed by pressing and a through vulcanization during the day. Stoichiometric ratio of investigated blend compositions is 0.5 .

Table 1. Characteristics of the powders heat-resistant materials [4-6] where $D_{32}$ - average volume-surface diameter $S_{s p}$ - specific surface.

\begin{tabular}{|c|c|c|c|c|}
\hline Additive & $D_{32}$, microns & $S_{s p}, \mathrm{~m}^{2} / \mathrm{g}$ & $T_{\mathrm{m}}, \mathrm{K}$ & $T_{\mathrm{b}}, \mathrm{K}$ \\
\hline $\mathrm{Al}$ (АСД-4) & 4.34 & 0.38 & 933 & 2759 \\
\hline $\mathrm{B}$ (Б-99A) & 0.92 & 2.83 & 2450 & 3931 \\
\hline $\mathrm{Si}$ & 0.81 & 3.19 & 1696 & 2873 \\
\hline $\mathrm{TiO}_{2}$ (nano) & 0.015 & 148 & 2128 & 3200 \\
\hline $\mathrm{TiO}_{2}$ (analytical grade) & 2.4 & 0.65 & 2128 & 3200 \\
\hline
\end{tabular}

This is an Open Access article distributed under the terms of the Creative Commons Attribution License 4.0, which permits unrestricted use, 


\section{Research methods}

The reactivity of heterogeneous systems was detected using experiments on ignition incandescent body, the luminous flux and the rate of combustion. Tests were carried out in air at atmospheric pressure. Ignition timing is determined by the appearance of the flame.

When conductive heating patterns lit by direct contact with a heated metal block. [7] In the tests we measured the temperature of the metal block and the delay time of ignition. Temperature measurement error of \pm 1 degree. Deviation measurement results of the average delay time values in parallel experiments did not exceed $12 \%$.

Investigation of the process of ignition in a radiant heating was carried out on installing radiant heating "Uranium 1" [3]. The radiation of the xenon lamp DKSR-10000 focused by the elliptical reflector spot with a diameter of $12 \mathrm{~mm}$. Light intensity was measured by a micro calorimeter with an error not exceeding $10 \%$. Exposure light flux asked by a butterfly valve. Opening time (closing) the shutter is $4 \%$ of the exposure time. In experiments fixed exposure time and the time of appearance of the flame.

Samples of $10 \mathrm{~mm}$ and a height of $0.6 \mathrm{~mm}$ was lit in the range of heat fluxes $\left[(20-170) \mathrm{W} / \mathrm{cm}^{2}\right]$. In order to determine the absorbed energy ignition studied heterogeneous systems was measured reflection coefficient of the surface of the sample in the wavelength range 0.36-1.1 micron.

To determine the rate of burning mixed compositions using cylindrical samples with a diameter of $1 \mathrm{~mm}$ and a height of $30 \mathrm{~mm}$. Samples stayed on the side surface of the linoleum in acetone solution. The average rate of combustion in air at atmospheric pressure is defined by the movement of the combustion front along the sample. Burning time recorded with a stopwatch. The scatter of experimental data on the burning rate of less than $4 \%$. The results of measurement of the burning rate shown in Table 2.

Table 2. Characteristics of the model compositions, where M - the composition of the matrix model

\begin{tabular}{|c|c|c|c|c|c|c|}
\hline \multirow{2}{*}{ Structure } & $\begin{array}{c}\rho, \\
\mathrm{g} / \mathrm{cm}^{3}\end{array}$ & reflectivity, $\%$ & \multicolumn{3}{|c|}{ The ballistic characteristics of the compositions } \\
\cline { 4 - 7 } & & & $\begin{array}{c}\text { The burning rate, } \\
\mathrm{mm} / \mathrm{s}\end{array}$ & $\begin{array}{c}\text { Energy } \\
\text { ignition } \\
\mathrm{W} / \mathrm{cm}^{2}\end{array}$ & $\mathrm{~kJ} / \mathrm{mol}$ & $\begin{array}{c}Q \cdot z, \\
\mathrm{~g} \cdot \mathrm{with}\end{array}$ \\
\hline $\mathrm{M}$ & 1.67 & 15.3 & $1.20 \pm 0.05$ & 24.5 & 119.70 & $1.5 \cdot 10^{14}$ \\
\hline $\mathrm{M}+\mathrm{B}$ & 1.66 & 13.0 & $1.25 \pm 0.05$ & 13.6 & 165.35 & $8 \cdot 10^{13}$ \\
\hline $\mathrm{M}+\mathrm{Si}$ & 1.64 & 11.9 & $1.15 \pm 0.05$ & 19.1 & 145.25 & $2.3 \cdot 10^{13}$ \\
\hline $\begin{array}{c}\mathrm{M}+\mathrm{TiO} \\
\text { (nano) }\end{array}$ & 1.65 & 12.8 & $1.80 \pm 0.04$ & 14.4 & 173.55 & $3 \cdot 10^{14}$ \\
\hline $\begin{array}{c}\text { M+TiO } \\
\text { analytical } \\
\text { grade) }\end{array}$ & 1.66 & 12.6 & $1.10 \pm 0.02$ & 18.0 & 158.50 & $1.7 \cdot 10^{16}$ \\
\hline
\end{tabular}

It also shows the values of the absorption of the energy needed to ignite the blend compositions in the thermal radiation flux equal to $\mathrm{q}=50 \mathrm{~W} / \mathrm{cm} 2$. The results of the ignition compositions mixed on a heated unit shown in Fig. The experimental data on ignition heated block processed under thermal model [7] and are presented in the following coordinates and $X=1 / T_{s}, Y=\lg \left[t_{3} \cdot T_{s} /\left(T_{s}-T_{H}\right)^{3 / 2}\right]$, where $T_{s}$ - Block temperature; $T_{n}$ - the initial temperature of the sample; $t_{3}$ - delay time of ignition. 


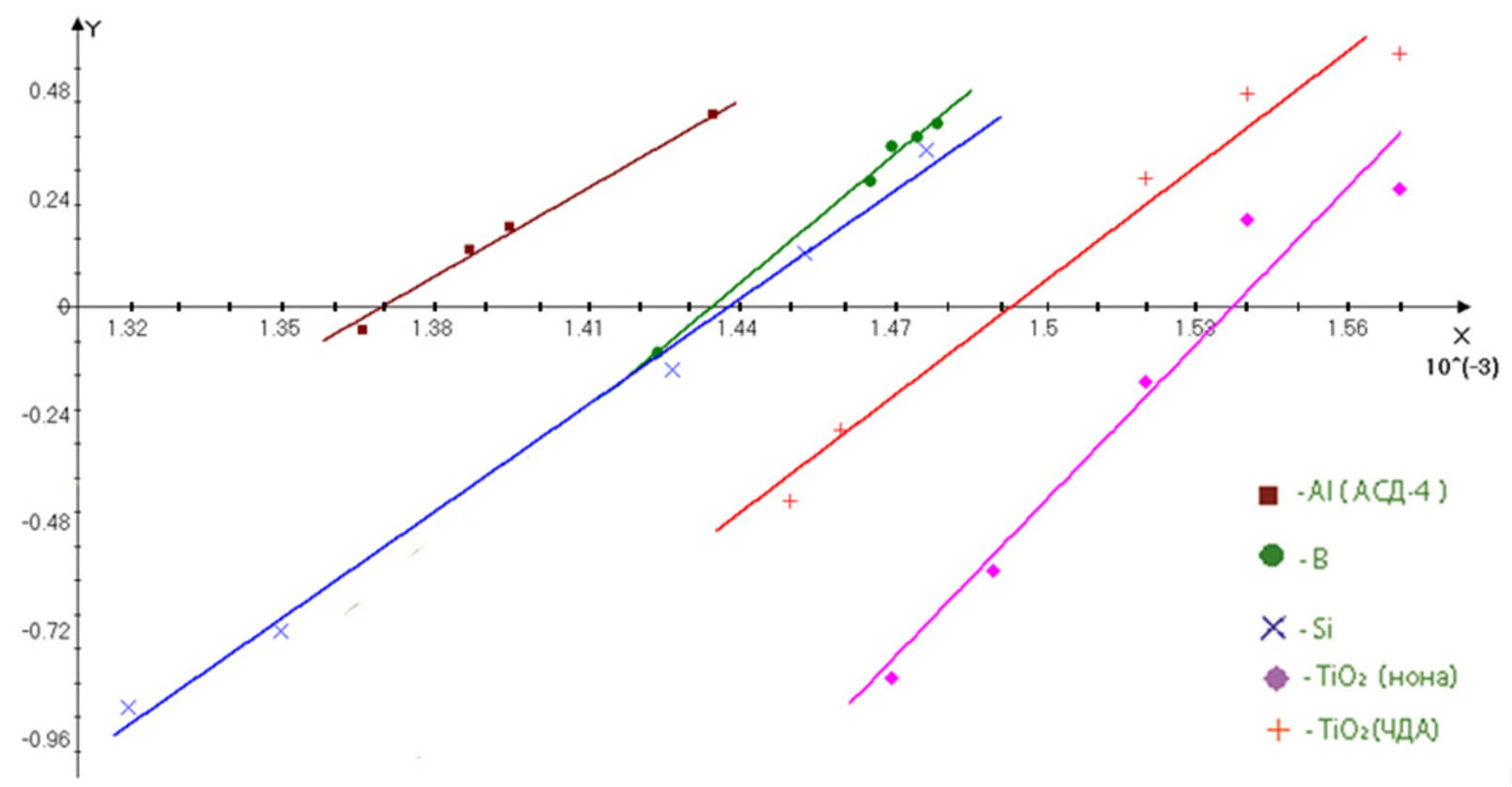

Figure 1. Ignition heterogeneous systems heated unit

It is evident that the experimental data for each composition is well fit to the line, therefore, it can be argued that the ignition process is limited by the test compounds in the condensed phase, and to describe it applies solid state thermal model [7].

Using the formula of the thermal model can be found kinetic parameters of ignition: $E$ - activation energy and the product of $Q \cdot z$, where $Q$ - the heat of reaction in a phase, and $z$ - pre-exponential factor. The values of $E$ and $Q \cdot z$ are shown in Table 2.

\section{Conclusion}

The results of the test can make the ranks of the degree of activity supplements the action of heat-resistant. For example:

- By reducing the flammability of heterogeneous systems we have a number of heated block: $\mathrm{TiO}_{2}($ nano $)>\mathrm{TiO}_{2}$ (analytical grade) $>\mathrm{Si}>\mathrm{B}>\mathrm{ACD}-4$;

- By reducing flammability in heating radiation flux: $\mathrm{B}>\mathrm{TiO}_{2}$ (nano) $>\mathrm{TiO}_{2}$ (analytical grade) $>\mathrm{Si}>\mathrm{B}>\mathrm{ACD}-4$;

- By reducing the rate of combustion systems studied: $\mathrm{TiO}_{2}$ (nano) $>\mathrm{B}>\mathrm{ACD}-4>\mathrm{Si}>\mathrm{TiO}_{2}$ (analytical grade).

It can be seen that the selected additives depending on test conditions uniquely affected by the delay time of ignition and rate of combustion of heterogeneous systems. This may be caused by characteristics changes of the optical properties of the samples, their density and other characteristics. Nevertheless, we can confidently assert that there is a correlation between the reactivity of heterogeneous systems and the degree of dispersion of the studied heat-resistant additives in their composition.

Therefore, evaluation of the effectiveness of the influence of various additives on the ballistic performance of heterogeneous systems must necessarily take into account the specific surface additives.

Funding was provided by Tomsk State University Competitiveness Improvement Program (Project № 8.2.46.2015).

\section{References}

1. V. Boldyrev, Methods for Studying the Kinetics of the Thermal Decomposition of Solids (Tomsk, TSU Publishing House, 1958)

2. L. Demenkova, N. Kundo, Combust, 10, 41 (1974)

3. V. Arkhipov, A. Korotkikh, V. Kuznetsov, Chemical Physics, 26, 58 (2007)

4. A. Macek, Y. Semple, Combustion Sience and Technology, 1, 181 (1969)

5. A. Birat, A. Korolchenko, G. Kravchuk, Pozharovzryvoopasnost Substances and Materials and Their Means of Extinguishing (Chemistry, 1990)

6. G. Samsonov, T. Bulakkova, A. Burykina Physical and Chemical Properties of Oxides (Moscow, Metallurgy, 1969)

7. V. Vilyunov, Ignition Theory of Condensed Matter (Novosibirsk, Nauka, 1984) 